\title{
Antimicrobial resistance and virulence factors in Escherichia coli from Swedish dairy calves
}

\author{
Kerstin de Verdier ${ }^{*}$, Ann Nyman $^{\dagger}$, Christina Greko and Björn Bengtsson $^{\dagger}$
}

\begin{abstract}
Background: In Sweden, knowledge about the role of enteropathogenic Escherichia coli in neonatal calf diarrhea and the occurrence of antimicrobial resistance in E. coli from young calves is largely unknown. This has therapeutic concern and such knowledge is also required for prudent use of antimicrobials.

Methods: In a case control study Esherichia coli isolated from faecal samples from dairy calves were phenotyped by biochemical fingerprinting and analyzed for virulence genes by PCR. Antimicrobial susceptibility was tested by determination of minimum inhibitory concentration (MIC). Farm management data were collected and Fisher's exact test and univariable and multivariable logistic regression analysis were performed.
\end{abstract}

Results: Of 95 E. coli tested for antimicrobial susceptibility $61 \%$ were resistant to one or more substances and $28 \%$ were multi-resistant. The virulence gene F5 (K99) was not found in any isolate. In total, 21 out of 40 of the investigated virulence genes were not detected or rarely detected. The virulence genes espP, irp, and fyuA were more common in resistant $E$. coli than in fully susceptible isolates $(P<0.05)$. The virulence gene ter $Z$ was associated with calf diarrhea $(P \leq 0.01)$.

The participating 85 herds had a median herd size of 80 lactating cows. Herds with calf diarrhea problems were larger (> 55 cows; $P<0.001)$, had higher calf mortality $(P \leq 0.01)$ and calf group feeders were more in use $(P>$ $0.05)$, compared to herds without calf diarrhea problems.

There was no association between calf diarrhea and diversity of enteric E. coli.

Conclusions: Antimicrobial resistance was common in E. coli from pre-weaned dairy calves, occurring particularly in calves from herds experiencing calf diarrhea problems. The results indicate that more factors than use of antimicrobials influence the epidemiology of resistant E. coli.

Enteropathogenic E. coli seems to be an uncommon cause of neonatal calf diarrhea in Swedish dairy herds. In practice, calf diarrhea should be regarded holistically in a context of infectious agents, calf immunity, management practices etc. We therefore advice against routine antimicrobial treatment and recommend that bacteriological cultures, followed by testing for antimicrobial susceptibility and for virulence factors, are used to guide decisions on such treatment.

\section{Background}

Neonatal calf diarrhea (NCD) is a major disease worldwide when calves are reared intensively, and constitute substantial cost in terms of calf mortality, opportunity costs for labor and capital, veterinary costs and loss in calf value. The term NCD generally refers to a disease complex characterized by acute, undifferentiated diarrhea in young calves. It is a multifactorial disease where,

\footnotetext{
* Correspondence: kerstin.de-verdier@sva.se

+ Contributed equally

Department of Animal Health and Antimicrobial Strategies, National Veterinary Institute, 75189 Uppsala, Sweden
}

besides the causative pathogenic agent, calf age, management and environmental factors, may influence the clinical outcome [1].

A large number of infectious agents have been incriminated as causes of NCD, including Salmonella and bovine viral diarrhea virus (BVDV). Commonly reported causative pathogens are rotavirus, coronavirus, Cryptosporidium spp and enteropathogenic Escherichia coli (E. coli) [2-5]. Enteric colibacillosis is manifested primarily by varying degrees of diarrhoea and dehydration and the outcome may be fatal. The major virulence factors of enteropathogenic strains of $E$. coli in NCD are the F5

\section{Biomed Central}


(K99) adhesion antigen and also the heat-stable enterotoxin (ST) [6]. Under Swedish conditions, E. coli is of practitioner's concern from a therapeutic perspective. In most cases of NCD in Swedish dairy calves antimicrobial therapy is not indicated since most enteric E. coli strains from calves are non pathogenic [7]. However, for treatment of enteritis caused by enteropathogenic E. coli, or of $E$. coli bacteraemia secondary to enteritis, antimicrobials given orally or systemically are recommended [8]. Knowledge of the susceptibility is necessary for elaboration of guidelines on prudent use of antimicrobials.

Although it is a potential pathogen, E. coli is a normal inhabitant of the gastrointestinal tract of most warm blooded animals and one of the most common representatives of the aerobic gram-negative microbiota. Such commensal bacteria can be reservoirs for transferable resistance genes and thereby reflect the selective pressure from use of antimicrobials in a population $[9,10]$. Enteric $E$.coli from healthy animals is therefore recommended as indicators for prevalence of resistance in animal populations [11] and used in several monitoring programs.

In Sweden, the role of enteropathogenic E. coli in NCD is only fragmentarily known [7,12-14]. Likewise, the knowledge on occurrence of antimicrobial resistance in $E$. coli from young calves is scarce. Therefore, the aim of this study was to investigate among E. coli from preweaned dairy calves the occurrence of virulence genes and of antimicrobial resistance and their association. The aim was also to evaluate the association between the occurrence of NCD and antimicrobial resistance, virulence genes and potential risk factors.

\section{Methods}

\section{Herds}

Field veterinary practitioners all over Sweden were invited to submit samples from dairy herds by their own choice, for a case/control study. One inclusion criterion was BVDV-free dairy herds; $i$ e. participation in the national BVD control program and declared free from BVDV. Other inclusion criteria were $>29$ cows, and that case and control herds should have experienced $>6$ and $<3$ diarrhoeic calves respectively, out of the 20 most recently born.

\section{Samples}

Samples were collected from March 2004 to June 2005. Faecal samples were collected as rectal swabs. According to instructions, case/control pairs of calves should be sampled, comprising one healthy (i. e. no signs of diarrhoea) calf in each control herd (CD-) and one calf with acute diarrhoea in each case herd $(\mathrm{CD}+)$. Case/control pairs should comprise calves of equal age, and all the sampled calves should be between one day and four weeks old. Calves should not have been treated with antimicrobials within two weeks prior to sampling. The samples were submitted by ordinary mail to the Swedish National Veterinary Institute (SVA), and arrived there the day after sampling.

\section{Questionnaire}

Data were collected from the farmers by a questionnaire. Questions were asked about the herd (number of cows, number of unweaned calves); calf age, breed and gender; calf management (time for cow-calf separation ("< 24 h after birth", "1-3 days after birth" and ">3 days after birth"), age at weaning, feeding (use of calf group feeder) and rearing systems); routines for antimicrobial treatment (use of dihydrostreptomycin ${ }^{1}$ (DHS) orally for treatment of diarrhoea ("never", "sometimes", or "often") and use of other antimicrobials orally for treatment of diarrhoea ("never", "sometimes", or "often"); calf mortality (of the 20 most recently born calves); information on calf health i.e. general appearance of sampled calves ("not affected", "slightly to moderately affected", and "severely affected"), number of calves with diarrhoea in the herd (of the 20 most recently born calves), diarrhea consistency ("soft", "watery" and "bloody"), diarrhea duration ("1 day", "2 days" and "3 days"), respiratory signs ("yes" and "no").

\section{Bacteriological culture}

The samples were streaked on horse blood agar (5\% v/v) and on MacConkey agar and incubated at $37^{\circ} \mathrm{C}$ for $18 \mathrm{~h}$. From each sample, 25 colonies that morphologically corresponded to E. coli were sub-cultured on horse blood agar [15]. Isolates were confirmed as E. coli by testing for production of tryptophanase (indole) and $\beta$ glucuronidase ( $\mathrm{p}$-nitrophenyl- $\beta$-D-glucopyanosiduronic acid, PGUA). Only lactose-positive isolates with typical morphology and positive reaction in both tests were selected for further analysis.

All 25 selected $E$. coli isolates from each sample were phenotyped by biochemical fingerprinting [16]. Briefly, the method is based on evaluation of the kinetics of biochemical reactions and performed in micro titer plates containing 11 different dehydrated reagents (The Phene Plate System; PhP-system, Biosys AB, Stockholm, Sweden). The isolates were hence clustered into different $\mathrm{PhP}$ types, describing the diversity of $E$. coli in the sample. Based on the biochemical fingerprinting, one isolate representing the dominant phenotype in each sample was selected for testing of antimicrobial susceptibility and virulence genes.

\section{Analysis of antimicrobial susceptibility}

Antimicrobial susceptibility was tested by determination of minimum inhibitory concentration (MIC) using a 
microdilution method. Testing was performed according to recommendations by CLSI (formerly NCCLS) (NCCLS, 2002) using VetMICTM panels (National Veterinary Institute, Uppsala, Sweden) and cat ion adjusted Mueller-Hinton broth (Becton Dickinson, Cockeysville, USA). Antimicrobials and range of concentrations tested are given in Table 1 . The quality control strain, E. coli ATCC 25922, tested in parallel with each batch of isolates, was on all occasions within acceptable ranges. Apart from florfenicol the tested antimicrobials are, or have been, licensed for use in cattle in Sweden.

Isolates were classified as susceptible or resistant based on epidemiological cut-off values issued by European Committee on Antimicrobial Susceptibility Testing (EUCAST; http://www.escmid.org). These cut-off values classify an isolate as resistant to an antimicrobial when its MIC is distinctly higher than those of inherently susceptible, "wild type", strains of the bacterial species. For sulphametoxazole no cut-off value is available from EUCAST, therefore a provisional value was set according to the principles for epidemiological cut-off values. Cut off-values used are given in Table 1.

\section{Analysis of virulence genes}

Isolates were analyzed for 10 different virulence genes (F4, F5, F6, F18, F41, STa, STb, LT, EAST, VT2e) by PCR at SVA (inhouse PCR, Swedish National Veterinary Institute). A subset of isolates were tested for an additional 30 virulence genes (VT1,VT2, eae, beta, gamma, alpha, kappa, epsilon, fimA, fimB, fim C, fimH, fimE, fliC, etpD, bfpA, hlyA, espA, espB, espP, katP, terA, terC, ter $W$, terE, terZ, ehly1, irp, fyuA, astA) by PCR at the Veterinary Laboratories Agency (VLA), Weybridge, UK (RM La Ragione personal communication). The subset of isolates, selected with attention to differences in calf age and geographical location, were submitted in cryotubes with agar by ordinary mail to VLA.

\section{Statistical methods}

This study was performed as a case-control study, where the calf was the study unit and the dependent variable was disease status, classified as case (calves diagnosed with diarrhea; $\mathrm{CD}+$ ) or control (calf diagnosed not to have diarrhea; CD-). Unconditional associations between the dependent variable and each of the independent variables were first screened using Fisher's exact test and univariable logistic regression analysis. Variables with a $P$-value $\leq 0.20$, provided that there was no co linearity $(r<0.70)$ between variables, were then considered for further analysis. Collinearity between variables was assessed pair-wise by calculation of Spearman rank correlations.

Moreover, associations between antimicrobial resistance and presence of virulence genes in isolates of $E$. coli were investigated using the same analyses as in the case-control part of the study.

Continuous variables, not linearly related to the outcome, were categorized using the quartiles as cut-points, or by using biologically important, or recommended cut-points. Categories of categorical variables with too few observations were amalgamated when biological, or logical, new categories were possible to make. In other cases such categorical variables were not used in the analysis. Variables with many missing values (> 20\% missing observations) were not used in the multivariable analysis.

A multivariable model was constructed using manual stepwise backward logistic-regression analysis, where variables not significant in the model were re-entered whenever a new variable became significant, or a variable was removed. Potential confounders and intervening factors were considered in every model. A variable was considered as a confounder if the point estimates of the coefficients in a model changed $>20 \%$ with the potential confounder present. In the final model a variable with a $P$-value $\leq 0.05$ was considered statistically significant and retained in the model. Biologically plausible interactions between the main effects were tested in the final model. Herd was not included as a random factor due to too few observations per herd. However, the "cluster" command in Stata was used making the standard errors allow for intragroup correlation.

The fit of the models was evaluated with the HosmerLemeshow goodness-of-fit test with the data partitioned into 10 deciles. The statistical analyses were done using Stata Software (StataCorp., 2010; Stata Statistical Software: Release 11.0; College Station, TX, USA: StataCorp LP.).

\section{Results}

Samples were obtained from a total of 104 calves. From these, samples from 95 calves, representing 85 dairy herds, were used for laboratory and statistical analyses. Exclusion of samples was due to failure of isolating $E$. coli (no growth or overgrowth by Proteus spp). Of the 95 calves, 56 were diagnosed as having diarrhea.

All information about the herds was collected by the questionnaire used at the farm visit. However, all questions were not always fully answered for all herds, hence there are a varying number of missing values for the variables included in this study. The participating 85 herds were located in all geographical regions of Sweden with significant cattle population and had a median herd size of 80 lactating cows (50\% central range (CR): 40 140 cows). The calves were of both the Swedish red and white breed $(\mathrm{n}=51)$ and of the Swedish Holstein breed $(n=42)$. Forty-four of the calves were heifer calves and 49 were bull calves. The calves were separated from 
Table 1 Resistance (percent, $95 \% \mathrm{Cl}$ in brackets) and distribution (percent) of MICs for Escherichia coli $(\mathbf{n}=\mathbf{9 5})$.

\begin{tabular}{|c|c|c|c|c|c|c|c|c|c|c|c|c|c|c|c|c|c|c|c|c|c|}
\hline \multirow[t]{2}{*}{ Antimicrobial } & \multirow[t]{2}{*}{ Range tested $(\mathrm{mg} / \mathrm{L})$} & \multirow[t]{2}{*}{ Cut-off value (mg/L) } & \multirow[t]{2}{*}{ Resistance } & \multicolumn{18}{|c|}{ Minimum Inhibitory Concentration (mg/L) } \\
\hline & & & & $\leq 0.03$ & 0.06 & 0.12 & 0.25 & 0.5 & 1 & 2 & 4 & 8 & 16 & 32 & 64 & 128 & 256 & 512 & 1024 & 2048 & $>2048$ \\
\hline Ampicillin & $0.25-32$ & $>8$ & $27.4(18.7-37.5)$ & & & & 0 & 0 & 11.6 & 48.4 & 12.6 & 0 & 0 & 1.1 & 26.3 & & & & & & \\
\hline Ceftiofur & $0.12-16$ & $>1$ & $0.0(0.0-3.8)$ & & & 0 & 38.9 & 53.7 & 7.4 & 0 & 0 & 0 & 0 & & & & & & & & \\
\hline Chloramphenicol & $1-128$ & $>16$ & $5.3(1.7-11.9)$ & & & & & & 1.1 & 9.5 & 74.7 & 9.5 & 0 & 0 & 0 & 0 & 5.3 & & & & \\
\hline Enrofloxacin & $0.03-4$ & $>0.12$ & $13.7(7.5-22.3)$ & 18.9 & 61.1 & 6.3 & 3.2 & 6.3 & 2.1 & 1.1 & 0 & 1.1 & & & & & & & & & \\
\hline Florfenicol & $4-32$ & $>16$ & $0.0(0.0-3.8)$ & & & & & & & & 66.3 & 30.5 & 3.2 & 0 & & & & & & & \\
\hline Gentamicin & $0.5-64$ & $>2$ & $0.0(0.0-3.8)$ & & & & & 25.3 & 68.4 & 6.3 & 0 & 0 & 0 & 0 & 0 & & & & & & \\
\hline Nalidixic acid & $1-128$ & $>16$ & $13.7(7.5-22.3)$ & & & & & & 2.1 & 31.6 & 51.6 & 1.1 & 0 & 1.1 & 3.2 & 4.2 & 5.3 & & & & \\
\hline Neomycin & $2-16$ & $>8$ & $5.3(1.7-11.9)$ & & & & & & & 87.4 & 5.3 & 2.1 & 0 & 5.3 & & & & & & & \\
\hline Streptomycin & $2-256$ & $>16$ & $44.2(34.0-54.8)$ & & & & & & & 1.1 & 16.8 & 32.6 & 5.3 & 2.1 & 14.7 & 8.4 & 10.5 & 8.4 & & & \\
\hline Sulphonamide & $16-2048$ & $>256$ & $31.6(22.4-41.9)$ & & & & & & & & & & 47.4 & 17.9 & 3.2 & 0 & 0 & 0 & 1.1 & 1.1 & 29.5 \\
\hline Tetracycline & $0.5-64$ & $>8$ & $31.6(22.4-41.9)$ & & & & & & 37.9 & 27.4 & 2.1 & 1.1 & 0 & 1.1 & 0 & 30.5 & & & & & \\
\hline Trimethoprim & $0.25-32$ & $>2$ & $5.3(1.7-11.9)$ & & & & 37.9 & 41.1 & 14.7 & 1.1 & 1.1 & 0 & 0 & 0 & 4.2 & & & & & & \\
\hline
\end{tabular}

Range of concentrations tested and cut-off values for resistance are indicated. MICs equal to or lower than the lowest concentration tested are given as the lowest tested concentration. MICs above the range of concentrations tested are given as the concentration closest to the range. MICs above the cut-off value for resistance are given in bold lettering. 
their dam $<24 \mathrm{~h}$ after birth $(\mathrm{n}=48), 1-3$ days after birth $(n=23)$ or after $>3$ days $(n=21)$. Calf group feeder was used in 36 of the herds.

On average 1.7 calf ( $50 \%$ CR: 0 - 3 calves) and 8.8 calves (50\% CR: 5 - 10 calves) out of the 20 latest born calves had had diarrhoea in herds with CD- calves and $\mathrm{CD}+$, respectively. In herds with $\mathrm{CD}$ - calves 0.5 calf of the 20 latest born calves (50\% CR: $0-1)$ had died, and in herds with $\mathrm{CD}+$ calves 1.4 calves of the 20 latest born calves (50\% CR: $0-2)$ had died.

Twenty-three of the CD+ calves were diagnosed with diarrhoea in the first 10 days after birth, 13 calves were diagnosed 11-21 days after birth, and 19 calves 22-135 days after birth. In the same periods 11,18 and 10 of the $\mathrm{CD}$ - calves were sampled. Of the diarrhoeic calves $70 \%$ had soft diarrhoea, $21 \%$ watery diarrhoea and $9 \%$ had blood in the faeces. Twenty-four percent of the calves were sampled one day after the onset of diarrhoea, 33\% two days after, $40 \%$ three days after, and 3\% 6-14 days after. The general appearance was affected in $56 \%$ of the CD+ calves (43.6\% "slightly to moderately"; $12.7 \%$ "severely"). None of the CD- calves had an affected general appearance. Only $9 \%$ of all participating calves had respiratory symptoms, and these were all CD + calves.

In $32 \%$ of the herds dihydrostreptomycin tablets (DHS) were occasionally used to treat diarrhoea, and in $44 \%$ of the herds other antimicrobials were used occasionally or often to treat diarrhoea.

E. coli was isolated in samples from all participating calves. One isolate from each calf $(\mathrm{n}=95)$ was analysed for antimicrobial susceptibility and 94 isolates for occurrence of 10 virulence genes. Moreover, 48 isolates (13 from calves with diarrhoea) were analysed for 30 additional virulence factors.

\section{Univariable analysis}

The result from the univariable analysis are presented in Table 2 and 3 for variables associated with being a CD+ or $\mathrm{CD}$ - calf and for variables associated with antimicrobial resistance in $E$. coli isolates $(\mathrm{P}<0.20)$.

\section{Herd factors}

There was no significant association between breed, gender, time to separation from dam, age of diagnosis and being a $\mathrm{CD}+$ or $\mathrm{CD}$ - calf $(P>0.05)$. However, both breed and age of diagnosis had a $\mathrm{P}$-value $<0.20$ and were considered for the multivariable regression analysis. There were a significant higher proportion of calves having diarrhoea, and a higher proportion of calves that had died, in herds with $\mathrm{CD}+$ calves than herds with $\mathrm{CD}$ calves $(\mathrm{P} \leq 0.01)$. $\mathrm{CD}+$ calves came from larger herds $(>$ 55 cows $)$ than $\mathrm{CD}$ - calves $(P<0.001)$, and from herds where it was more common with calf group feeder $(P<$ 0.05). The use of other antimicrobials than DHS to treat diarrhoea was more common in herds with $\mathrm{CD}+$ calves $(P<0.001)$.

\section{Diversity}

The median diversity of the E. coli isolates was 0.50 (50\% CR: 0.23 - 0.72). There was no significant difference in diversity between samples from $\mathrm{CD}+$ and $\mathrm{CD}$ calves. Also, there was no difference in diversity between samples where the dominating $\mathrm{PhP}$ type was resistant to one or more antimicrobials and where the dominating type was not resistant.

\section{Virulence genes}

Of the virulence genes, fimA, fimB, fim C, fimE, fimH, $f l i C$, and terA were found in $\geq 90 \%$ of the isolates, but there were no significant difference in findings between isolates from $\mathrm{CD}+$ or $\mathrm{CD}$ - calves. The virulence genes ter $Z$, ter $W$, espP, irp, fyuA, EAST and ast $A$ were found in $46 \%, 42 \%, 37.5 \%, 35 \%, 35 \%, 25 \%$ and $22 \%$ of the isolates, respectively. The gene ter $Z$ was significantly more often found in $E$. coli from $C D+$ calves than $C D$ - calves $(P \leq 0.01)$.

The virulence genes $b f p A$, espB, ehly1, F4, F5, F6, F18, and $L T$ were not found in any isolate. Moreover, in $\geq$ $87.5 \%$ of the isolates eae, espA, etpD, F41, hlyA, katP, $S T a, S T b$, terE, terC, $V T 1, V T 2$, and $V T 2 e$ were absent.

\section{Antimicrobial resistance}

Of the $95 \mathrm{E}$. coli tested for antimicrobial susceptibility $61 \%$ were resistant to one or more substances. Distribution of MIC values and percentages of $E$. coli resistant to the antimicrobials tested are presented in Table 1. Twenty-seven isolates (28\%) were multiresistant, i.e. resistant to three or more antimicrobials. Of these, 19 isolates had resistance to streptomycin, sulphonamide and tetracycline in the phenotype, usually in combination with other resistance traits. Significantly more isolates from $C D+$ calves than from $C D$ - calves were resistant to ampicillin, tetracycline or sulphonamide $(P$ $\leq 0.05$ ). Also multiresistance, including resistance to ampicillin, streptomycin, tetracycline and sulphonamide, was more common $(P \leq 0.01)$ among isolates from $\mathrm{CD}+$ calves. There was no significant association between antimicrobial resistance of the isolates and herd routines for use of DHS, or other antimicrobials, to treat diarrhoea.

\section{Virulence genes and associations with antimicrobial} resistance

The virulence genes espP, irp, and fyuA were more common in E. coli resistant to one or more antimicrobials than in fully susceptible isolates $(P<0.05)$.

\section{Multivariable analysis \\ Variables associated with being a $C D+$ or $C D$ - calf}

A total of 72 variables were screened in the univariable logistic regression analysis of variables associated with being a $\mathrm{CD}+$ or $\mathrm{CD}$ - calf. Of these 72 variables 10 (with 
Table 2 Results from the univariable logistic regression analysis of variables significantly (P $\leq 0$

\begin{tabular}{|c|c|c|c|c|}
\hline Variable & Level & Healthy calves & Diarrheic calves & P-value \\
\hline \multicolumn{5}{|l|}{ Herd factors } \\
\hline \multirow[t]{3}{*}{ Breed } & 0: Swedish red and white & 18 & 33 & \\
\hline & 1: Swedish Holstein & 21 & 21 & \\
\hline & 2: Other & 0 & 1 & $0.15^{*}$ \\
\hline \multirow[t]{3}{*}{ Age at weaning } & 0: 6-8 weeks of age & 22 & 20 & \\
\hline & 1: 9-11 weeks of age & 7 & 15 & \\
\hline & 2: $12-16$ weeks of age & 7 & 13 & $0.20^{*}$ \\
\hline \multirow[t]{3}{*}{ Proportion of dead calves/20 born calves } & $0: 0 \%$ & 24 & 19 & \\
\hline & 1: $5 \%$ & 11 & 12 & \\
\hline & $2: \geq 10 \%$ & 4 & 18 & 0.01 \\
\hline \multirow[t]{3}{*}{ Proportion of calves having diarrhea/20 born calves } & $0:<5 \%$ & 16 & 1 & \\
\hline & 1: $5-20 \%$ & 17 & 7 & \\
\hline & $2:>20 \%$ & 6 & 42 & $<0.001$ \\
\hline \multirow[t]{3}{*}{ Age at sampling } & $0: 0-11$ days & 11 & 23 & \\
\hline & 1: $12-21$ days & 18 & 13 & \\
\hline & $2: \geq 22$ days & 10 & 19 & $0.07^{*}$ \\
\hline \multirow[t]{3}{*}{ Herd size (no of cows) } & $0:<55$ & 21 & 10 & \\
\hline & 1: $55-120$ & 14 & 19 & \\
\hline & $2: \geq 121$ & 4 & 25 & $<0.001^{*}$ \\
\hline \multirow[t]{2}{*}{ Milk calf feeder? } & $0:$ No & 28 & 28 & \\
\hline & 1: Yes & 10 & 26 & $0.03^{*}$ \\
\hline \multirow[t]{2}{*}{ Usage of other antibiotics to treat diarrhea } & $0:$ Never & 30 & 20 & \\
\hline & 1: Sometimes/Often & 7 & 33 & $<0.001$ \\
\hline \multicolumn{5}{|l|}{ Antimicrobial resistance } \\
\hline \multirow[t]{2}{*}{ Resistant to ampicillin } & $0:$ No & 34 & 35 & \\
\hline & 1: Yes & 7 & 19 & $0.05^{*}$ \\
\hline \multirow[t]{2}{*}{ Resistant to streptomycin } & $0:$ No & 27 & 26 & \\
\hline & 1: Yes & 14 & 28 & $0.08^{*}$ \\
\hline \multirow[t]{2}{*}{ Resistant to tetracycline } & 0: No & 36 & 29 & \\
\hline & 1: Yes & 5 & 25 & $<0.01^{*}$ \\
\hline \multirow[t]{2}{*}{ Resistant to sulphonamide } & $0:$ No & 34 & 31 & \\
\hline & 1: Yes & 7 & 23 & $<0.01^{*}$ \\
\hline \multirow[t]{2}{*}{ Multiresistant (resistant to at least three antibiotics (Am, Sm, Tc and/or Su)) } & $0:$ No & 37 & 37 & \\
\hline & 1: Yes & 4 & 19 & $<0.01$ \\
\hline \multicolumn{5}{|l|}{ Presence of virulence genes } \\
\hline \multirow[t]{2}{*}{ Presence of terZ } & $0:$ No & 24 & 1 & \\
\hline & 1: Yes & 11 & 10 & $<0.01$ \\
\hline \multirow[t]{2}{*}{ Presence of astA } & O: No & 28 & 8 & \\
\hline & 1: Yes & 5 & 5 & 0.09 \\
\hline \multirow[t]{2}{*}{ Presence of EAST } & O: No & 33 & 37 & \\
\hline & 1: Yes & 6 & 18 & $0.06^{*}$ \\
\hline
\end{tabular}

* variables eligible for entering the multivariable analysis

a $P \leq 0.20$ and considered being potential risk factors) were eligible for entering the multivariable analysis (Table 2). However, there was a high correlation ( $r \geq$ 0.70 ) between herd size and milk calf feeder, as well as for presence of resistance against streptomycin and sulphonamide. Hence, of these variables, the variable with the lowest $P$-value in the univariable analysis were selected to be eligible for the multivariable analysis. In the final multivariable analysis of factors associated with being a $\mathrm{CD}+$ or a $\mathrm{CD}$ - calf three variables remained with a $P \leq 0.05$ (Table 4). There was an increased risk of being a $\mathrm{CD}+$ calf for a calf diagnosed at age $<11$ or $\geq 22$ days old compared to calves diagnosed at 12-21 days old. Moreover, there was a higher risk that a calf in a larger herd ( $\geq 120$ cows) was a CD+ calf than a calf in a smaller herd ( $<120$ cows), and that $\mathrm{CD}+$ calves more 
Table 3 Results from the univariable logistic regression analysis of variables significantly $(P \leq 0.20)$ associated with Escherichia coli isolates $(n=95)$ with or without antimicrobial resistance (from 95 healthy or diarrheic calves from 85 Swedish dairy herds).

\begin{tabular}{|c|c|c|c|c|}
\hline Variable & Level & $\begin{array}{l}\text { E. coli with antimicrobial } \\
\text { resistance }\end{array}$ & $\begin{array}{l}\text { E. coli without antimicrobial } \\
\text { resistance }\end{array}$ & $\begin{array}{l}P \text { - } \\
\text { value }\end{array}$ \\
\hline \multicolumn{5}{|l|}{ Herd factors } \\
\hline \multirow[t]{3}{*}{ Age at sampling } & $0: 0-11$ days & 24 & 10 & \\
\hline & 1: $12-21$ days & 13 & 16 & \\
\hline & $2: \geq 22$ days & 19 & 10 & $0.09^{*}$ \\
\hline \multirow[t]{2}{*}{ Any respiratory syndromes } & $0:$ No & 50 & 33 & \\
\hline & 1: Yes & 7 & 1 & 0.10 \\
\hline \multirow[t]{3}{*}{ Herd size (no of cows) } & $0:<55$ & 14 & 17 & \\
\hline & 1: $55-120$ & 20 & 13 & \\
\hline & $2: \geq 121$ & 21 & 6 & $0.04^{*}$ \\
\hline \multirow[t]{3}{*}{ Time for separation of cow and calf } & $0:<24 h$ after calving & 33 & 14 & \\
\hline & $\begin{array}{l}\text { 1: 1-3 days after } \\
\text { calving }\end{array}$ & 12 & 10 & \\
\hline & $\begin{array}{l}\text { 2: }>3 \text { days after } \\
\text { calving }\end{array}$ & 9 & 12 & $0.09^{*}$ \\
\hline \multirow{2}{*}{$\begin{array}{l}\text { Usage of DHS tablets to treat } \\
\text { diarrhea }\end{array}$} & $0:$ Never & 40 & 21 & \\
\hline & 1: Sometimes/Often & 15 & 15 & $0.20^{*}$ \\
\hline \multicolumn{5}{|l|}{ Presence of virulence genes } \\
\hline \multirow[t]{2}{*}{ Presence of espP } & $0:$ No & 11 & 19 & \\
\hline & 1: Yes & 15 & 3 & $0.002^{*}$ \\
\hline \multirow[t]{2}{*}{ Presence of irp } & $0:$ No & 12 & 19 & \\
\hline & 1: Yes & 14 & 3 & $0.003^{*}$ \\
\hline \multirow[t]{2}{*}{ Presence of fyuA } & o: No & 13 & 18 & \\
\hline & 1: Yes & 13 & 4 & $0.02^{*}$ \\
\hline
\end{tabular}

* variables eligible for entering the multivariable analysis

often had E. coli isolates that were resistant to tetracycline.

The final model showed reasonably good fit; the Hosmer-Lemeshow $\chi^{2}$ (8 d.f.) was $4.7(P=0.79)$.

Variables associated with antimicrobial resistance in E. coli isolates

A total of 58 variables were screened in the univariable logistic regression analysis of variables associated with antimicrobial resistance in E. coli isolates. Of these 58 variables 7 (with a $P \leq 0.20$, and considered being potential risk factors) were eligible for entering the multivariable analysis (Table 3). However, there was a high correlation $(\mathrm{r} \geq 0.70)$ between presence of irp and fyua, and the variable with the lowest $\mathrm{P}$-value in the univariable analysis was selected to be eligible for the multivariable analysis. It was not possible to make any final multivariable model since the only variable remaining with a $P$-value $\leq 0.05$ in the model was herd size.

\section{Discussion}

This study shows that antimicrobial resistance is widespread in enteric E. coli from healthy as well as from diarrheic preweaned dairy calves. Streptomycin, sulphonamide, tetracycline or ampicillin were the most prevalent resistance traits and isolates resistant to all these antimicrobials were common. The findings are in agreement with studies in preweaned dairy calves from other countries [17-22]. Also quite similar results were obtained from Swedish calves sampled at post-mortem [23]. In such calves a high occurrence of resistance can be anticipated since a large proportion of the animals are probably treated with antimicrobials. An equally high prevalence of resistant $E$. coli in the untreated calves of the present study is therefore remarkable.

As discussed by Call et al. [24] the epidemiology of resistant E. coli in calves is multifactorial, complex and e.g. influenced by co-selection due to linkage of resistance genes. But widespread resistance is fundamentally a consequence of historical and current use of antimicrobials and associations between use of antimicrobials and resistance in enteric $E$. coli of calves have been documented [19,20,22,25-28]. However, in the present study resistance is not a direct sequel to antimicrobial use since no calf was treated prior to sampling. Antimicrobial use in calves is still not uncommon in Sweden and Ortman \& Svensson [29] showed that in dairy herds 
about one third of diarrhoeic calves (1-90 days) were treated with trimethoprim/sulfa, enrofloxacin or other antimicrobials. Also in the present study NCD was treated with antimicrobials in several herds but there was no statistical association between such routines and resistance. Although the total use of antimicrobials in the herds is unknown, the absence of association indicates that the high prevalence of resistance is not solely an effect of a direct selection pressure by use of antimicrobials to the calves.

Importance of other aspects than antimicrobial use on prevalence of resistant $E$. coli in preweaned calves is indicated by several studies $[17,20-22,26,28,30]$ and was recently reviewed by Call et al. [24]. One proposed factor is a linkage between resistance genes and genes conferring selective advantage to colonize the intestinal lumen of calves. Walk et al. [28] hypothesized that, regardless of use of antimicrobials, tetracycline resistance in $E$. coli is co-selected in calves by an unknown "beneficial mutation". Likewise, Khachatryan et al. $[21,30]$ showed that $E$. coli with the resistance phenotype streptomycin - sulfonamide - tetracycline have a selective advantage to colonize the intestine of calves given a dietary milk supplement also in absence of antimicrobials. Notably, in the present study about one third of the resistant isolates and two thirds of the multiresistant isolates had streptomycin - sulfonamide - tetracycline in their phenotype.

A selective advantage of resistant strains due to dietary differences is in agreement with the age related occurrence of resistant $E$. coli documented elsewhere [18-20,22,28,31]. The importance of age is evident also on comparison of data from the present study to previous data from older cattle in Sweden, in which resistant E. coli are rare [23].

Another factor of possible importance for resistance in preweaned calves is feeding milk from cows treated with antimicrobials or feeding colostrum from cows treated in the dry period $[17,20,32,33]$. It has been proposed

Table 4 Final multivariable logistic regression analysis of variables significantly $(P \leq 0$

\begin{tabular}{lccccc}
\hline Variable & $\boldsymbol{\beta}$ & $\mathbf{S . E .}(\boldsymbol{\beta})$ & $\mathbf{O R}^{\mathbf{a}}$ & $\mathbf{9 5 \%} \mathrm{Cl}\left(\mathbf{O R}^{\mathrm{a}}\right)$ & $\boldsymbol{P}$-value \\
\hline Intercept & 1.24 & 0.57 & - & - & - \\
Herd size & & & & & \\
0: $\geq 121$ & Ref $^{\mathrm{b}}$ & - & - & - & - \\
1: $55-120$ & -1.52 & 0.74 & 0.22 & $0.05 ; 0.93$ & 0.04 \\
2: $<55$ & -2.28 & 0.70 & 0.10 & $0.03 ; 0.40$ & 0.001 \\
Resistant to tetracycline? & & & & & \\
0:No & Ref $^{\mathrm{b}}$ & - & - & - & - \\
1:Yes & 1.66 & 0.64 & 5.25 & $1.48 ; 18.6$ & 0.01 \\
\hline
\end{tabular}

${ }^{\mathrm{a} O R}=$ Odds ratio

${ }^{\mathrm{b}}$ Ref $=$ reference category that antimicrobial residues of such milk could select for resistance in the enteric flora of calves. Although there are few studies to support the assumptions, the risk of a "hidden" selection pressure in dairy calves warrants further studies of the issue.

In the present study, resistance was more common in E. coli from calves with diarrhea than in isolates from healthy calves. Also multivariate analysis showed that resistance to tetracycline in $E$. coli was associated with diarrhea in calves. A higher occurrence of resistance in E. coli in calves from herds experiencing problems with NCD was shown also by Gunn et al. [34]. A plausible reason for this is that antimicrobials are used more often in herds with a high disease incidence, as indicated in the present study by the more common routine of treating NCD with antimicrobials in CD+ herds than in $\mathrm{CD}$ - herds. However, a higher prevalence of resistant $E$. coli in calves with diarrhoea could also be due to linkage between virulence genes and resistance genes as proposed by Martinez \& Baquero [35]. Such linkage was demonstrated in E. coli from pigs with diarrhoea [36,37] and could imply co-selection of virulence genes by use of antimicrobials and conversely maintenance of resistance in populations of pathogenic bacteria as proposed by Boerlin et al. [36]. In the present study phenotypic resistance to one or more antimicrobials was associated with presence of the virulence genes espP, irp or fyuA in E. coli. However, there was no association to single antimicrobials or resistance phenotypes. Moreover, none of these virulence factors were associated with diarrhea and the findings should be interpreted with caution. Likewise, Suojala et al. [38] found an association between the virulence factor $i u c D$ and resistance to streptomycin, ampicillin, sulphametoxazole and trimethoprim in $E$. coli from dairy cows with mastitis, but they found no association between the virulence factor and patogenicity.

Attention has been drawn by veterinary practitioners to the possibility that $E$. coli is a more prevalent cause of NCD than demonstrated in previous Swedish studies, restricted to E. coli with virulence factor F5. This suggestion is supported by international studies showing a higher prevalence of E. coli F5 than in the Swedish studies [39-42]. This virulence gene was not found in any isolate in this study and 21 out of 40 of the investigated genes were not detected or rarely detected. Although the number of isolates tested was small, this contradicts a common occurrence of enteropathogenic E. coli in NCD. A possible exception is $E$. coli with the virulence gene ter $Z$ which was associated with diarrhea. However, further studies are needed to clarify clinical relevance of these virulence genes in NCD.

The etiology of diarrhea in this study was not clarified, since other infectious agents than $E$. coli were not 
searched for. The impact of Salmonella and BVDV, however, was most likely none, since the prevalence of Salmonella spp is low in Swedish cattle herds [43] and all the participating herds were declared BVD-free.

In the present study there was no association between diversity of enteric $E$. coli and calf diarrhea. A decrease in the homogeneity of the faecal coliform flora has been shown in suckling pigs with diarrhea [44]. Therefore, biochemical fingerprinting was performed to increase the probability of selecting isolates of the pathogenic strain and thereby the probability of detecting virulence genes. The results in the present study agree with the findings of Acha et al. [39] and could indicate that in calves, there is no predominance of single clones even in diarrhea caused by enteropathogenic E. coli. Still, in the present study it more likely indicates that diarrhea caused by E. coli was uncommon since there, with one exception, was no association between occurrence of virulence genes and diarrhea.

In most studies of antimicrobial susceptibility in intestinal bacteria, isolates are randomly selected from a culture of intestinal content. But in the present study, isolates of the most common phenotype in each sample was selected for testing. This did not influence the overall prevalence of resistance in the group of calves sampled, but in individual calves it occasionally had a profound effect on the outcome of the susceptibility test. Accordingly, to guide the choice of antimicrobial therapy it can be misleading to test $E$. coli with undefined clinical relevance. Moreover, this emphasizes the advantage of identifying pathogenic isolates for susceptibility testing, possibly by detection of virulence factors.

Sampled calves deviated slightly from the given inclusion criteria, i e 0-3 (CD-) and 5-10 (CD+) of the 20 most recently born calves had been diarrheic, as compared to $0-2$ (CD- criterion) and $>6(\mathrm{CD}+$ criterion). Other sampling errors were a mismatch in age at sampling between $\mathrm{CD}+$ and $\mathrm{CD}$ - calves, and an extended age interval for $\mathrm{CD}+$ and $\mathrm{CD}$ - calves (1-135 days, mean 21.9) compared to the criteria (four weeks). Nevertheless, there were clear differences in clinical signs between $\mathrm{CD}$ - and $\mathrm{CD}+$ calves and $\mathrm{CD}$ - and $\mathrm{CD}+$ herds regarding mortality, occurrence of diarrhea, general appearance and respiratory signs. One contributing reason for this could be that CD+ herds were larger than CD- herds. Larger herds were more likely to have calf group feeder in the present study, and there might be a larger number of neonatal calves in the herd during the same time period which increases the risk for infectious enteric diseases. The association between diarrhea in calves and large herd size agrees with the findings in a recent Swedish study on calf morbidity and mortality in herds with different size (C Sandgren personal communication). The calf mortality in this study was higher than previously reported in Swedish herds [45] which also could reflect a negative impact of large herd size on calf health. Calf rearing practices have changed concurrently with herd size.

\section{Conclusions}

Antimicrobial resistance was common in E. coli from preweaned dairy calves and particularly in calves from herds experiencing problems with neonatal diarrhea. Resistance could not be associated to use of antimicrobials, implying that other factors also influence the epidemiology of resistant $E$. coli. Isolates with virulence genes were as common in calves with as without clinical signs.

In practice, neonatal calf diarrhea should be seen holistically in a context of infectious agents, calf immunity and management practices. This study indicates that enteropathogenic E. coli is an uncommon cause of NCD in Swedish dairy herds. We therefore advice against routine antimicrobial treatment and recommend that bacteriological cultures, followed by testing for antimicrobial susceptibility and for virulence factors, are used to guide decisions on such treatment

\section{Endnotes}

${ }^{1}$ Dihydrostreptomycin vet, tablets, Boehringer Ingelheim, Vetmedica, Malmö, Sweden

\section{Acknowledgements}

We express our gratitude to the participating veterinary practitioners for collecting samples and data, and to the dairy farmers for their cooperation. We thank Dr Ann Lindberg for participating in study design, Dr Anna Aspán and Dr RM La Ragioni for performing PCR, Ms Sigbrit Mattsson and Mrs. Verena Rehbinder for technical assistance, and Anita Jonasson, Lena Stengärde and Charlotte Sandgren for incriminating E. coli as a major pathogen in NCD.

We thank The Swedish Farmers' Foundation for Agricultural Research for funding the study.

\section{Authors' contributions}

$\mathrm{KdV}$ and $\mathrm{BB}$ designed and coordinated the study and drafted the manuscript. AN performed the statistical analysis and helped to draft the manuscript. CG participated in study design and helped to draft the manuscript. All authors read and approved the final manuscript.

\section{Competing interests}

The authors declare that they have no competing interests.

Received: 2 March 2011 Accepted: 26 January 2012

Published: 26 January 2012

\section{References}

1. Bruning-Fann C, Kaneene JB: Environmental and management risk factors associated with morbidity and mortality in perinatal and pre-weaning calves: a review from an epidemiological perspective. Vet Bull 1992, 62:399-413.

2. Gulliksen SM, Jor E, Lie KI, Hamnes IS, Loken T, Akerstedt J, Osteras O: Enteropathogens and risk factors for diarrhea in Norwegian dairy calves. J Dairy Sci 2009, 92:5057-5066.

3. Snodgrass DR, Terzolo HR, Sherwood D, Campbell I, Menzies JD, Synge BA: Aetiology of diarrhoea in young calves. Vet Rec 1986, 119:31-34. 
4. Tzipori S: The aetiology and diagnosis of calf diarrhoea. Vet Rec 1981, 108:510-515.

5. Tzipori S: The relative importance of enteric pathogens affecting neonates of domestic animals. Adv Vet Sci Comp Med 1985, 29:103-206.

6. Mainil JG, Bex F, Jacquemin E, Pohl P, Couturier M, Kaeckenbeeck A: Prevalence of four enterotoxin (STaP, STaH, STb, and LT) and four adhesin subunit (K99, K88, 987P, and F41) genes among Escherichia coli isolates from cattle. Am J Vet Res 1990, 51:187-190.

7. Bjorkman C, Svensson C, Christensson B, de Verdier K: Cryptosporidium parvum and Giardia intestinalis in calf diarrhoea in Sweden. Acta Vet Scand 2003, 44:145-152.

8. Constable PD: Antimicrobial use in the treatment of calf diarrhea. J Vet Intern Med 2004, 18:8-17.

9. Levin BR, Lipsitch M, Perrot V, Schrag S, Antia R, Simonsen L, Walker NM, Stewart FM: The population genetics of antibiotic resistance. Clin Infect Dis 1997, 24(Suppl 1):S9-16.

10. van den Bogaard AE, Stobberingh EE: Epidemiology of resistance to antibiotics. Links between animals and humans. Int J Antimicrob Agents 2000, 14:327-335.

11. Franklin A, Acar J, Anthony F, Gupta R, Nicholls T, Tamura Y, Thompson S, Threlfall EJ, Vose D, van Vuuren M, White DG, Wegener HC, Costarrica ML: Antimicrobial resistance: harmonisation of national antimicrobial resistance monitoring and surveillance programmes in animals and in animal-derived food. Rev Sci Tech 2001, 20:859-870.

12. de Verdier Klingenberg K, Svensson L: Group A rotavirus as a cause of neonatal calf enteritis in Sweden. Acta Vet Scand 1998, 39:195-199.

13. Torsein M, Lindberg A, Sandgren CH, Waller KP, Tornquist M, Svensson C: Risk factors for calf mortality in large Swedish dairy herds. Prev Vet Med 2011.

14. Viring S, Olsson SO, Alenius S, Emanuelsson U, Jacobsson SO, Larsson B, Linde N, Uggla A: Studies of enteric pathogens and gamma-globulin levels of neonatal calves in Sweden. Acta Vet Scand 1993, 34:271-279.

15. Kühn I, Katouli M, Wallgren P, Söderlind O, Möllby R: Biochemical fingerprinting as a tool to study the diversity and stability of intestinal microfloras. Microecology and Therapy 1995, 23:140-148.

16. Katouli M, Lund A, Wallgren P, Kuhn I, Soderlind O, Mollby R: Metabolic fingerprinting and fermentative capacity of the intestinal flora of pigs during pre- and post-weaning periods. J Appl Microbiol 1997, 83:147-154

17. Berge AC, Atwill ER, Sischo WM: Animal and farm influences on the dynamics of antibiotic resistance in faecal Escherichia coli in young dairy calves. Prev Vet Med 2005, 69:25-38.

18. Berge AC, Hancock DD, Sischo WM, Besser TE: Geographic, farm, and animal factors associated with multiple antimicrobial resistance in fecal Escherichia coli isolates from cattle in the western United States. J Am Vet Med Assoc 2010, 236:1338-1344.

19. DeFrancesco KA, Cobbold RN, Rice DH, Besser TE, Hancock DD: Antimicrobial resistance of commensal Escherichia coli from dairy cattle associated with recent multi-resistant salmonellosis outbreaks. Vet Microbiol 2004, 98:55-61.

20. Dolejska M, Senk D, Cizek A, Rybarikova J, Sychra O, Literak I: Antimicrobial resistant Escherichia coli isolates in cattle and house sparrows on two Czech dairy farms. Res Vet Sci 2008, 85:491-494.

21. Khachatryan AR, Hancock DD, Besser TE, Call DR: Role of calf-adapted Escherichia coli in maintenance of antimicrobial drug resistance in dairy calves. Appl Environ Microbiol 2004, 70:752-757.

22. Sato K, Bartlett PC, Saeed MA: Antimicrobial susceptibility of Escherichia coli isolates from dairy farms using organic versus conventional production methods. J Am Vet Med Assoc 2005, 226:589-594.

23. SVARM 2009: Swedish Veterinary Antimicrobial Resistance Monitoring. ISSN 1650-6332. In Book Swedish Veterinary Antimicrobial Resistance Monitoring. ISSN 1650-6332. Edited by: Björn Bengtsson, Stina Englund, Christina Greko, Ulrika Grönlund Andersson. City: National Veterinary Institute, Uppsala, Sweden; 2010:

24. Call DR, Davis MA, Sawant AA: Antimicrobial resistance in beef and dairy cattle production. Anim Health Res Rev 2008, 9:159-167.

25. Berge AC, Moore DA, Sischo WM: Field trial evaluating the influence of prophylactic and therapeutic antimicrobial administration on antimicrobial resistance of fecal Escherichia coli in dairy calves. App/ Environ Microbiol 2006, 72:3872-3878.

26. Kaneene JB, Warnick LD, Bolin CA, Erskine RJ, May K, Miller R: Changes in multidrug resistance of enteric bacteria following an intervention to reduce antimicrobial resistance in dairy calves. Journal of clinical microbiology 2009, 47:4109-4112.

27. Platt TM, Loneragan GH, Scott HM, Norby B, Thomson DU, Brown MS, Ives SE, Brashears MM: Antimicrobial susceptibility of enteric bacteria recovered from feedlot cattle administered chlortetracycline in feed. Am J Vet Res 2008, 69:988-996.

28. Walk ST, Mladonicky JM, Middleton JA, Heidt AJ, Cunningham JR, Bartlett P, Sato K, Whittam TS: Influence of antibiotic selection on genetic composition of Escherichia coli populations from conventional and organic dairy farms. Appl Environ Microbiol 2007, 73:5982-5989.

29. Ortman K, Svensson C: Use of antimicrobial drugs in Swedish dairy calves and replacement heifers. Vet Rec 2004, 154:136-140.

30. Khachatryan AR, Besser TE, Hancock DD, Call DR: Use of a nonmedicated dietary supplement correlates with increased prevalence of streptomycin-sulfa-tetracycline-resistant Escherichia coli on a dairy farm. Appl Environ Microbiol 2006, 72:4583-4588.

31. Hoyle DV, Knight HI, Shaw DJ, Hillman K, Pearce MC, Low JC, Gunn GJ, Woolhouse ME: Acquisition and epidemiology of antibiotic-resistant Escherichia coli in a cohort of newborn calves. J Antimicrob Chemother 2004, 53:867-871.

32. Di Labio E, Regula G, Steiner A, Miserez R, Thomann A, Ledergerber U: Antimicrobial resistance in bacteria from Swiss veal calves at slaughter. Zoonoses Public Health 2007, 54:344-352.

33. Langford FM, Weary DM, Fisher L: Antibiotic resistance in gut bacteria from dairy calves: a dose response to the level of antibiotics fed in milk. J Dairy Sci 2003, 86:3963-3966.

34. Gunn GJ, Hall M, Low JC: Comparison of antibiotic resistance fo Escherichia coli populations isolated from groups of diarrhoeic and control calves. Vet J 2003, 165:172-174.

35. Martinez $J \mathrm{~L}$, Baquero F: Interactions among strategies associated with bacterial infection: pathogenicity, epidemicity, and antibiotic resistance. Clin Microbiol Rev 2002, 15:647-679.

36. Boerlin P, Travis R, Gyles CL, Reid-Smith R, Janecko N, Lim H, Nicholson V, McEwen SA, Friendship R, Archambault M: Antimicrobial resistance and virulence genes of Escherichia coli isolates from swine in Ontario. Appl Environ Microbiol 2005, 71:6753-6761.

37. Travis RM, Gyles CL, Reid-Smith R, Poppe C, McEwen SA, Friendship R, Janecko N, Boerlin P: Chloramphenicol and kanamycin resistance among porcine Escherichia coli in Ontario. The Journal of antimicrobial chemotherapy 2006, 58:173-177

38. Suojala L, Pohjanvirta T, Simojoki H, Myllyniemi AL, Pitkala A, Pelkonen S, Pyorala S: Phylogeny, virulence factors and antimicrobial susceptibility of Escherichia coli isolated in clinical bovine mastitis. Vet Microbiol 2010.

39. Acha SJ, Kuhn I, Jonsson P, Mbazima G, Katouli M, Mollby R: Studies on calf diarrhoea in Mozambique: prevalence of bacterial pathogens. Acta Vet Scand 2004, 45:27-36.

40. Uhde FL, Kaufmann T, Sager H, Albini S, Zanoni R, Schelling E, Meylan M: Prevalence of four enteropathogens in the faeces of young diarrhoeic dairy calves in Switzerland. Vet Rec 2008, 163:362-366.

41. Wieler LH, Sobjinski G, Schlapp T, Failing K, Weiss R, Menge C, Baljer G Longitudinal prevalence study of diarrheagenic Escherichia coli in dairy calves. Berl Munch Tierarztl Wochenschr 2007, 120:296-306.

42. Younis EE, Ahmed AM, El-Khodery SA, Osman SA, El-Naker YF: Molecular screening and risk factors of enterotoxigenic Escherichia coli and Salmonella spp. in diarrheic neonatal calves in Egypt. Res Vet Sci 2009, 87:373-379.

43. Anonymous: Surveillance of zoonotic and other animal disease agents in Sweden 2009, ISSN 1654-7098. In Book Surveillance of zoonotic and other animal disease agents in Sweden 2009, ISSN 1654-7098. Edited by: Ulla Carlsson, Elina Lahti, Marianne Elvander. City: National Veterinary Institute, Uppsala, Sweden; 2010:.

44. Kuhn I, Katouli M, Lund A, Wallgren P, Möllby R: Phenotypic diversity and stability of the intestinal coliform flora in piglets during the first 3 months of age. Microb Ecol Health Dis 1993, 6:101-107.

45. Olsson SO, Viring S, Emanuelsson U, Jacobsson SO: Calf diseases and mortality in Swedish dairy herds. Acta Vet Scand 1993, 34:263-269.

doi:10.1186/1751-0147-54-2

Cite this article as: de Verdier et al.: Antimicrobial resistance and virulence factors in Escherichia coli from Swedish dairy calves. Acta Veterinaria Scandinavica 2012 54:2 